\title{
GEORGES PEREC E A GÊNESE DA LITERATURA COMPARADA
}

\author{
Renata Lopes Araujo*
}

\section{Resumo}

O objetivo deste artigo é estabelecer as diferenças entre dois textos que, aparentemente, têm muito em comum, Crítica literária, história literária, literatura comparada, do crítico Paul Van Tieghen, e $A$ viagem de inverno, do escritor Georges Perec. Apesar das grandes semelhanças - que podem conduzir o leitor a pensar até na hipótese de plágio -, os dois textos são fruto de concepções de literatura muito diferentes, e a relação entre eles põe em prática um princípio de escritura caro a Perec, o da intertextualidade.

Palavras-chave: Georges Perec, literatura comparada, Le voyage d'hiver, intertextualidade, crítica literária

\section{Abstract}

The aim of this paper is to establish the differences between two texts that appear to have much in common, Literary criticism, literary history, comparative literature, by Paul Van Tieghen, and $A$ viagem de inverno, written by Georges Perec. Despite the strong similarities - that can lead the reader to think even of a simple copy -, the two texts are the result of very different conceptions of literature, and their relationship puts into practice a principle of scripture dear to Perec, the intertextuality.

Keywords: Georges Perec, comparative literature, Le voyage d'hiver, intertextuality, literary criticism

* Doutoranda em Literatura junto à área de Estudos Linguísticos, Literários e Tradutológicos da Faculdade de Filosofia, Letras e Ciências Humanas da Universidade de São Paulo. 
V ocê é um(a) professor(a), estudante de Letras ou simplesmente alguém que se interessa por literatura e crítica literária. Um dia, você ouve falar de um livro sobre literatura comparada, uma coletânea de textos considerados fundadores para a disciplina. Como o assunto lhe interessa, você resolve procurá-lo em uma biblioteca, ou adquiri-lo em uma livraria. Chegando em casa começa a lê-lo, e encontra um texto intitulado Crítica literária, história literária, literatura comparada, escrito por Paul Van Tieghen, no qual o autor se propõe, inicialmente, a descrever as etapas pelas quais passamos no contato com uma obra literária.

O texto chama sua atenção por dois motivos: ele se dirige diretamente a quem o lê (tal como esse artigo) e por começar contando uma estória particular, na qual o protagonista - o leitor - está em uma casa no campo, impossibilitado de sair por vários dias, e sua única distração é explorar a vasta biblioteca de seus anfitriões. Felizmente, o leitor gosta muito de literatura e folheia muitos títulos com maior ou menor interesse.

Após algum tempo, o leitor decide selecionar algumas obras para fazer uma análise mais profunda. A partir dessa análise, ele começa a estabelecer relações entre esses livros e outros lidos no passado, e tenta compreender por que alguns o agradam mais que outros. Depois disso o leitor poderá, eventualmente, encontrar algum texto crítico sobre as obras lidas, e assim terá a opinião de estudiosos para reforçar ou contradizer suas próprias impressões.

Tudo isso faz surgir no espírito do leitor uma grande curiosidade sobre os autores daqueles livros: como eram suas relações com os contemporâneos, se fizeram parte de algum movimento literário, quais influências os formaram e em qual tradição se inserem. Procurando um pouco mais, o leitor encontra edições críticas, monografias e algumas histórias da literatura que o ajudam a ter uma ideia de como se constitui a forma literária escolhida pelos autores.

Se você, interessado(a) em literatura, tem contato não apenas com as obras canônicas e aprecia igualmente textos mais recentes, já pode ter ouvido falar de um escritor francês chamado Georges Perec. E se você conhece um pouco de seus escritos, é possível que já tenha lido $A$ viagem de inverno, um de seus últimos livros. Se você o leu, deve ter ficado espantado(a) com as semelhanças existentes entre a trama dessa obra e o início do texto de Van Tieghen. Mas se você não o conhece, saiba que se trata de um pequeno livro no qual um 
jovem pesquisador, Vincent Degraël, é convidado a passar alguns dias na casa dos pais de um amigo, no campo. Antes de voltar a Paris, Vincent encontra $A$ viagem de inverno, livro de um certo Hugo Vernier, e qual não é a surpresa do rapaz ao descobrir neste expressões e versos que figuravam em muitos poemas de autores importantes do Simbolismo e do Parnasianismo francês. E como Vincent escrevia justamente uma tese sobre alguns desses autores, assim que começou a ler o texto:

teve uma sensação de mal-estar que lhe foi impossível definir com precisão, mas que se acentuava à medida que virava as páginas do volume, com a mão cada vez mais trêmula: era como se as frases que tinha diante dos olhos se tornassem de chofre familiares, fazendo-o irresistivelmente lembrar alguma coisa, como se à leitura de cada uma delas se impusesse, ou antes superpusesse, a lembrança ao mesmo tempo precisa e frouxa de uma frase quase idêntica que ele já lera em algum lugar. (PEREC, 2004, p. 76-77)

Vincent descobre que $A$ viagem de inverno havia sido publicado antes das obras de Mallarmé, Lautréamont, Moréas, Rimbaud, Verlaine e outros, o que fazia do livro um "original", ou melhor, a fonte de boa parte da poesia francesa do século XIX. O pesquisador decide procurar outras informações sobre Hugo Vernier, mas morre em um hospital psiquiátrico sem descobrir quase nada sobre o misterioso escritor, nem conseguir outro exemplar de seu livro.

Você decide então verificar as datas dos textos e descobre que o de Van Tieghen é de 1931, quando Perec ainda nem era nascido. Sua primeira reação é a de encarar A viagem de inverno como um plágio de Crítica literária, história literária e literatura comparada. No entanto, você sabe que na obra de Perec as primeiras impressões geralmente não são definitivas e, sendo uma pessoa curiosa, decide procurar informações sobre essa "coincidência". E, para tal, é necessário voltar ao texto do crítico francês, que se serve da pequena estória inicial para esquematizar o "movimento natural do espírito no conhecimento da literatura" (TIEGHEN, 1994, p. 9): escolha da obra a ser lida (baseada em 
juízos de valor, isto é, o que se considera literário), fruição e admiração causadas pelo aspecto artístico, análise crítica subjetiva e busca de informações a fim de situar os autores com relação à tradição. Assim sendo, de acordo com o crítico, o caminho do texto no espírito do leitor especializado - pois é esse o leitor visado por Van Tieghen - conduz naturalmente ao estudo da história literária, dentro do qual muitas áreas devem ser abordadas pelo estudioso de literatura, tais como as influências formadoras da obra, as etapas de sua gênese, seu conteúdo, seu estilo, sua repercussão junto ao público, recepção da crítica, textos escritos tendo-a como "fonte", etc.

Van Tieghen enfatiza a importância da identificação e análise, tanto da "origem" quanto dos textos a partir dela derivados, para que o historiador da literatura possa ter uma visão mais completa da obra com a qual trabalha:

\begin{abstract}
Como um quadro, uma estátua, uma sonata, um livro também se insere numa série, esteja o autor consciente ou não de tal fato. Ele terá tido precursores; e terá sucessores. A história literária deve situá-lo no gênero, na forma de arte, na tradição à qual pertence, e apreciar a originalidade do autor, medindo o que ele herdou e o que ele criou. (TIEGHEN, 1994, p. 92)
\end{abstract}

O crítico ainda ressalta a falta de fecundidade presente no contato entre obras escritas em um mesmo país, e exorta o historiador literário a buscar as influências advindas de literaturas estrangeiras, contemporâneas ao autor e/ ou antigas. Para realizar essa difícil tarefa, Van Tieghen propõe a "divisão do trabalho" entre a história literária e uma disciplina especial, a literatura comparada, que prolongaria

os resultados obtidos pela história literária de uma nação, reunindo-os com os que, por seu lado, obtiveram os historiadores de outras literaturas, e desta rede complexa de influência se constitui[ria] um domínio à parte. (TIEGHEN, 1994, p. 96) 
Partindo do ponto de vista do crítico, uma das grandes motivações para o surgimento dos estudos de literatura comparada teria sido a necessidade de se estudar mais profundamente as influências exercidas pelos textos uns sobre os outros, com especial destaque para a relação entre literaturas de países diferentes. A importância do texto parece ser medida principalmente por seus antecessores e sucessores, e não tanto pelas inovações por ele trazidas. E essa também é a visão do protagonista de Vincent Degraël, pois sua busca por informações sobre Hugo Vernier parece estar essencialmente ligada:

a um sistema de pensamento que foi por muito tempo predominante na academia francesa. Sendo Degraël descrito como um jeune professeur de lettres que prepara uma tese sobre l'évolution de la poésie française des Parnassiens aux Symbolistes (...) esse sistema parece apontar para a crítica literária historicista (encerrada no conceito de "evolução" da poesia) que pretende estabelecer (e fechar) o sentido de um texto a partir daqueles que the serviram de "fonte" ou "origem" e determinar o fio histórico da "verdade" sobre os sistemas literários. (MURAD, 2007, p. 69)

Embora utilize um pano de fundo bastante parecido, a visão de Perec sobre o assunto é completamente diferente.

A estória (e principalmente o fracasso) de Vincent coloca em evidência uma mudança importante sofrida pelos estudos literários: o abandono da predominância da crítica do tipo lansoniano - para a qual a importância de um texto residia principalmente em suas origens, nos textos dos quais partiu - e a valorização do trabalho de releitura feito a partir dos textos e do diálogo estabelecido entre eles, a chamada intertextualidade. O fato de mostrar Degraël como um crítico literário ligado às noções de fonte e influência, caras à velha crítica cujos pressupostos, na época da publicação d'A viagem de inverno, já haviam sido suficientemente questionados, pode ser parte de uma vontade de Perec de acelerar um pouco a mudança de expectativa do leitor comum. O autor d' $A$ vida modo de usar sempre afirmou a importância de outros textos como pon- 
to de partida de sua obra, e valorizou o trabalho de comparação e mesmo de confronto entre os textos. Entre o desejo de se tornar um escritor realista e os livros escritos sob esta ótica, existe a escritura, ou seja, a passagem obrigatória pelos textos de outros, a partir da qual é possível escrever algo particular. Para o autor de Les Choses, escrever é sobretudo um processo de revisitação: “[...] lorsque j'écris, tous les sentiments que j'éprouve, toutes les idées que j'ai [...] ont déjà été traversées par des expressions, par des formes qui, elles, viennent de la culture du passé" (PEREC, 1992, p. 46). Assim sendo, um escritor não tem escolha: ele só pode se formar a partir da repetição de outros escritores, e não o faz apenas com o intuito de lhes prestar homenagem ou de inserir sua obra em uma espécie de "linhagem".

Assim sendo, ainda que utilize o mesmo pano de fundo, Perec chega a uma conclusão totalmente oposta à de Van Tieghen e, ao mesmo tempo, põe em prática a teoria da reutilização dos textos tal como a entendia. Tal como o crítico, o autor de 53 Jours apresenta uma alternativa à história literária, mas diferentemente do que vemos em Crítica literária [...], propõe um outro olhar para os textos "base", que considera enquanto matéria potencial para a criação de novas obras e não mais os vê como objeto digno de reverências pertencente ao passado, mas busca incorporá-los ao novo e ao presente. Esta é, essencialmente, a prática da visão perecquiana da literatura como um quebra-cabeças, isto é, como uma imagem composta por peças cujo sentido se forma apenas quando colocadas juntas. Todo escritor está cercado por muitos outros, lidos ou não; com eles, esse escritor faz parte de um conjunto inconcluso, cujos espaços vazios devem ser ocupados pela obra à venir. Inacabada também é a literatura, sempre à espera de novos textos e leitores.

\section{Nota}

O presente artigo foi publicado originalmente na Gláuks - Revista de Letras e Artes, v. 11, n. 2, p. 261-268, jul./dez. 2011, da Universidade Federal de Viçosa. 


\section{Referências}

LAFON. Michel. Borges ou la réécriture. Paris: Seuil, 1990.

MURAD, Samira. Le voyage d'hiver de Georges Perec: leitura e potencialidade, leitura como potencialidade. 2007. Dissertação (Mestrado em Literatura Francesa). Faculdade de Filosofia, Letras e Ciências Humanas, Universidade de São Paulo, São Paulo. Inédita.

PEREC, Georges. "Pouvoirs et limites du romancier français contemporain". In: COULET, H. (org.) Idées sur le roman. Paris: Larousse, 1992. p. 31-47.

. A coleção particular, seguido de A viagem de inverno. Tradução de Ivo Barroso. São Paulo: Cosac Naify, 2004.

TIEGHEN, Paul Van. "Crítica literária, história literária, literatura comparada". In: COUTINHO, Eduardo de Faria.; CARVALHAL, Tânia Franco. (org.) Literatura comparada: textos fundadores. Rio de Janeiro: Rocco, 1994. p. 89-96. 